\title{
openheart Prospective cohort study of elderly patients with coronary artery disease: impact of frailty on quality of life and outcome
}

\author{
Shouaib Qayyum (1D ,1,2 Jennifer Ann Rossington (10), ${ }^{3}$ Raj Chelliah, ${ }^{3}$ Joseph John, ${ }^{3}$ \\ Benjamin J Davidson, ${ }^{3}$ Richard M Oliver, ${ }^{3}$ Dumbor Ngaage, ${ }^{4}$ Mahmoud Loubani, ${ }^{4}$ \\ Miriam J Johnson, ${ }^{5}$ Angela Hoye ${ }^{6}$
}

To cite: Qayyum S,

Rossington JA, Chelliah R, et al. Prospective cohort study of elderly patients with coronary artery disease: impact of frailty on quality of life and outcome. Open Heart 2020;7:e01314. doi:10.1136/

openhrt-2020-001314

Received 17 April 2020

Revised 19 June 2020

Accepted 21 July 2020

\section{Check for updates}

C) Author(s) (or their employer(s)) 2020. Re-use permitted under CC BY-NC. No commercial re-use. See rights and permissions. Published by BMJ.

${ }^{1}$ Cardiology, Royal Stoke University Hospital, Stoke-onTrent, UK

${ }^{2}$ Academic Cardiology, Castle Hill Hospital, Cottingham, UK ${ }^{3}$ Cardiology, Castle Hill Hospital, Hull, UK

${ }^{4}$ Cardiothoracic Surgery, Castle Hill Hospital, Cottingham, UK ${ }^{5}$ Wolfson Palliative Care Research Centre, Hull York Medical School, University of Hull, Hull, United Kingdom ${ }^{6}$ Centre for Atherothrombosis and Metabolic Disease, Hull York Medical School, University of Hull, Hull, United Kingdom

Correspondence to Dr Shouaib Qayyum; shouaib. qayyum@gmail.com

\section{ABSTRACT}

Background Elderly, frail patients are often excluded from clinical trials so there is lack of data regarding optimal management when they present with symptomatic coronary artery disease (CAD).

Objective The aim of this observational study was to evaluate an unselected elderly population with CAD for the occurrence of frailty, and its association with quality of life (QoL) and clinical outcomes.

Methods Consecutive patients aged $\geq 80$ years presenting with CAD were prospectively assessed for frailty (Fried frailty phenotype (FFP), Edmonton frailty scale (EFS)), QoL (Short form survey (SF-12)) and comorbidity (Charlson Comorbidity Index (CCI)). Patients were re-assessed at 4 months to determine any change in frailty and QoL status as well as the clinical outcome.

Results One hundred fifty consecutive patients with symptomatic $C A D$ were recruited in the study. The mean age was $83.7 \pm 3.2$ years, $99(66.0 \%)$ were men. The clinical presentation was stable angina in $68(45.3 \%)$, the remainder admitted with an acute coronary syndrome including 21 (14.0\%) with ST-elevation myocardial infarction. Frailty was present in $28 \%$ and $26 \%$ by FFP and EFS, respectively, and was associated with a significantly higher $\mathrm{CCl}(7.5 \pm 2.4$ in frail, $6.2 \pm 2.2$ in prefrail, $5.9 \pm 1.6$ in those without frailty, $p=0.005)$. FFP was significantly related to the physical composite score for QoL, while EFS was significantly related to the mental composite score for QoL $(p=0.003)$. Treatment was determined by the cardiologist: percutaneous coronary intervention in $51(34 \%)$, coronary artery bypass graft surgery in 15 $(10 \%)$ and medical therapy in $84(56 \%)$. At 4 months, 14 $(9.3 \%)$ had died. Frail participants had the lowest survival. Cardiovascular symptom status and the mental composite score of QoL significantly improved $(52.7 \pm 11.5$ at baseline vs $55.1 \pm 10.6$ at follow-up, $p=0.04$ ). However, overall frailty status did not significantly change, nor the physical health composite score of QoL (37.2 \pm 11.0 at baseline vs $38.5 \pm 11.3$ at follow-up, $p=0.27$ ).

Conclusions In patients referred to hospital with CAD, frailty is associated with impaired QoL and a high coexistence of comorbidities. Following cardiac treatment, patients had improvement in cardiovascular symptoms and mental component of QoL.

\section{Key questions}

What is already known about this subject?

- Frailty and coronary artery disease are both prevalent and often coexist in older adult patients.

- Frail cardiovascular patients have been shown to have poor clinical outcomes especially when faced with external stressors like surgery and interventions.

- An increasing number of percutaneous coronary intervention $(\mathrm{PCl})$ procedures are being carried out in older adult patients.

What does this study add?

- Frailty is significantly related to health-related quality of life (QoL) in an octogenarian population with symptomatic coronary artery disease and is a predictor of poor survival irrespective of the treatment they undergo.

- $\mathrm{PCl}$ in frail older adult patients showed improvement in symptoms and mental composite scores of QoL but no significant improvement in physical composite scores of QoL.

How might this impact on clinical practice?

- Frailty can offer further risk stratification in older adult patients presenting with symptomatic coronary artery disease and can help identify patients who are unlikely to experience any significant improvement in their health-related QoL despite undergoing $\mathrm{PCl}$.

\section{INTRODUCTION}

Life expectancy is rising and as the prevalence of coronary artery disease (CAD) increases with age, ${ }^{1}$ a growing number of elderly patients are presenting with symptomatic CAD. This has translated into year-onyear increases in the number of revascularisation procedures (both percutaneous coronary intervention (PCI) and coronary artery bypass graft surgery (CABG)) in patients aged $\geq 80$ years. ${ }^{2}$ In this advanced age group, 
long-term mortality benefits seen with cardiovascular interventions is offset by a relatively limited lifespan; therefore, control of symptoms and preserving quality of life (QoL) are important considerations rather than longevity. ${ }^{3}$

The evidence base to guide management of elderly patients is limited. A review of major trials in cardiovascular disease indicated that $50 \%$ of trials failed to enrol any participant above 75 years of age. ${ }^{4}$ Indeed, only $9 \%$ of trial participants were aged $>75$ years, and only $2 \%$ were $>85$ years of age. The reasons are multifactorial but include increased comorbidities that exclude trial participation as well as reluctance to commit to the burden of additional hospital visits.

Importantly, interventions may incur increased procedural risks as compared with younger patients. ${ }^{5}$ However, it is important to be able to identify and risk stratify those older patients who are most likely to benefit from invasive interventional procedures. 'Frailty' amalgamates several key physiological processes. It takes into account the loss of functional reserves which makes these individuals vulnerable to a poor outcome in the face of any physiological stressor such as an acute coronary syndrome. ${ }^{6}$ Frailty, QoL and comorbidity assessment tools may help us to better understand the prognosis of elderly patients and provide a basis for evidence-based decision-making. ${ }^{7}$

Previous registries have indicated that frail patients undergoing PCI or CABG have a poorer outcome and higher mortality. ${ }^{89}$ However, these patients have been selected for the intervention, and these studies do not therefore consider patients who are managed medically. An overview of the entire population is needed in order to better guide decision-making in elderly patients. Therefore, we sought to assess the occurrence and impact of frailty in an unselected elderly population with CAD, irrespective of clinical presentation or treatment. We evaluated the relationship of frailty with QoL and determined any association with short-term survival.

\section{METHODS}

We recruited 150 consecutive patients aged $\geq 80$ years with symptomatic CAD between June 2016 and January 2017. This single-centre prospective observational study included patients across the whole spectrum of CAD; those with stable angina as well as inpatients with acute coronary syndromes (unstable angina (UA), non-STelevation myocardial infarction (NSTEMI) and ST-elevation myocardial infarction (STEMI)). Participants were recruited from the cardiology and cardiothoracic departments at Castle Hill Hospital in Hull. This is a tertiary referral centre in the North of England serving a population of 1.2 million. Patients with established heart failure and severe valvular heart disease if indicated by their previous medical records were excluded. Patients with advanced dementia and significant cognitive impairment who were unable to consent or understand the questionnaires were excluded from the study.
The primary objective was to evaluate the relationship between frailty and QoL. Participants were assessed for frailty using validated tools. ${ }^{11}{ }^{11}$ Briefly, the Fried frailty phenotype (FFP) evaluates patients for weight loss, level of exhaustion, physical activity, gait speed and grip strength. ${ }^{10}$ The Edmonton frailty scale (EFS) also evaluates weight loss and physical capability but in addition has some assessment of cognitive function and mood. ${ }^{11}$ Disability was defined as at least one disability determined by the IADL (Independent activity of daily living) score collected as part of the EFS. QoL was assessed using Short survey form-12 (SF-12). ${ }^{12}$ The QoL scores were compared with a control population matched for age and sex. ${ }^{13}$ Assessments were done at baseline and again at 4 months. Patients presenting with STEMI were included into the study after they had undergone PCI. The intensity of angina symptoms was classified according to the Canadian Cardiovascular Society (CCS).$^{14} 15$ Patients presenting with STEMI were allocated CCS class IV. Shortness of breath was categorised according to the New York Heart Association. ${ }^{16}$ Predicted mortality risk was assessed using the Global Registry of Acute Coronary Events Score (GRACE) ${ }^{17}$ and the surgical EuroScore II. ${ }^{18}$

Major adverse cardiovascular events (MACEs) were defined as death, acute myocardial infarction, stroke and major bleeding as defined by the Bleeding Academic Research Consortium Scale. ${ }^{19}{ }^{20}$ Detailed demographic and clinical characteristics of the participants were recorded to explore factors associated with frailty and QoL in the study cohort.

\section{Statistical analysis}

The sample size of 150 participants was used to explore the relationship between frailty and QoL and not powered for statistical significance. Hence, all findings of the analyses are reported as associations. Continuous variables are expressed as mean with SD, while categorical data are expressed as numbers and percentages. The relationship of frailty and QoL was evaluated using both simple and multiple linear regression models. Transformations were not used to meet the model assumptions. Missing values were omitted. Patients were categorised into nonfrail, pre-frail and frail depending on their FFP scores. The EFS categorised patients into non-frail, vulnerable, mild, moderate and severe frailty groups. Demographic and clinical parameters were compared with further define the characteristics of patients in each of these groups. Chi-square test was used to compare categorical variables and ANOVA was used for continuous variables. Participants' clinical and demographic variables were included in a regression model to better understand the relationship with QoL physical composite score (PCS) and mental composite score (MCS). The predictor variables were chosen on the basis of previously published work, indicating a relationship with QoL or which had a plausible biological rationale. Variables showing a statistically significant relationship in univariate analysis, and those which were of particular interest, were entered 
Coronary artery disease

Table 1 Baseline characteristics of the overall study cohort and according to Fried frailty status

\begin{tabular}{|c|c|c|c|c|c|}
\hline & \multirow[b]{2}{*}{ Total cohort $(n=150)$} & \multicolumn{3}{|c|}{ Fried frailty phenotype } & \multirow[b]{2}{*}{$P$ value } \\
\hline & & Non-frail $n=19$ & Pre-frail $n=89$ & Frail $n=42$ & \\
\hline Age & $83.7 \pm 3.2$ & $82.2 \pm 1.8$ & $83.6 \pm 3.3$ & $84.4 \pm 3.4$ & 0.04 \\
\hline Female & $51(34.0 \%)$ & $3(15.8 \%)$ & $29(32.6 \%)$ & $19(45.2 \%)$ & 0.07 \\
\hline Body mass index & $27.3 \pm 4.7$ & $26.2 \pm 2.8$ & $27.2 \pm 4.6$ & $27.9 \pm 5.5$ & 0.41 \\
\hline Hypertension & $102(68 \%)$ & $13(68.4 \%)$ & $61(68.5 \%)$ & $28(66.7 \%)$ & 0.98 \\
\hline Diabetes mellitus & $40(26.7 \%)$ & $4(21.1 \%)$ & $25(28.1 \%)$ & $11(26.2 \%)$ & 0.27 \\
\hline Previous myocardial infarction & $65(43.3 \%)$ & $5(26.3 \%)$ & $34(38.2 \%)$ & $26(61.9 \%)$ & 0.01 \\
\hline Previous $\mathrm{PCl}$ & $53(35.3 \%)$ & $5(26.3 \%)$ & $28(31.5 \%)$ & $20(47.6 \%)$ & 0.13 \\
\hline Previous CABG & $18(12 \%)$ & $2(10.5 \%)$ & $9(10.1 \%)$ & $7(16.7 \%)$ & 0.55 \\
\hline $\mathrm{h} / 0 \mathrm{CKD}$ & $1(0.7 \%)$ & $0(0.0 \%)$ & $0(0.0 \%)$ & $1(2.4 \%)$ & \\
\hline Charlson comorbidity score & $6.5 \pm 2.24$ & $5.9 \pm 1.6$ & $6.2 \pm 2.2$ & $7.5 \pm 2.4$ & 0.005 \\
\hline \multirow[t]{4}{*}{ Presentation } & $68(45.3 \%)$ & $10(52.6 \%)$ & $44(49.4 \%)$ & $14(33.3 \%)$ & 0.73 \\
\hline & $16(10.7 \%)$ & $2(10.5 \%)$ & $9(10.1 \%)$ & $5(11.9 \%)$ & \\
\hline & $45(30 \%)$ & $5(26.3 \%)$ & $24(26.9 \%)$ & $16(38.1 \%)$ & \\
\hline & $21(14 \%)$ & $2(10.52 \%)$ & $12(13.5 \%)$ & $7(16.7 \%)$ & \\
\hline \multirow[t]{2}{*}{ CCS angina class } & $12(8.0 \%)$ & $2(10.5 \%)$ & $6(6.7 \%)$ & $4(9.5 \%)$ & 0.03 \\
\hline & $19(12.7 \%)$ & $4(21.1 \%)$ & $9(10.1 \%)$ & $6(14.3 \%)$ & \\
\hline NYHA class & $9(6 \%)$ & $0(0 \%)$ & $1(1.1 \%)$ & $8(19.0 \%)$ & \\
\hline \multirow[t]{4}{*}{ LV function $(n=111)$} & $55(49.5 \%)$ & $7(46.7 \%)$ & $29(45.3 \%)$ & $20(57.1 \%)$ & 0.50 \\
\hline & $25(22.5 \%)$ & $2(13.3 \%)$ & $15(23.4 \%)$ & $9(25.7 \%)$ & \\
\hline & $20(18 \%)$ & $3(20 \%)$ & $12(18.8 \%)$ & $5(14.3 \%)$ & \\
\hline & $11(9.9)$ & $3(20.0 \%)$ & $8(12.5 \%)$ & $1(2.9 \%)$ & \\
\hline ECG & $24(16 \%)$ & $2(10.5 \%)$ & $11(12.4 \%)$ & $11(26.2 \%)$ & 0.10 \\
\hline \multirow[t]{6}{*}{ Blood parameters } & $126 \pm 18(123-129)$ & $126 \pm 4(117-135)$ & $128 \pm 2(124-132)$ & $122 \pm 2(118-127)$ & 0.32 \\
\hline & $52.6 \pm 19.9(49.4-55.8)$ & $55.3 \pm 3.2(48.5-62.1)$ & $54.3 \pm 2.1(50.2-58.4)$ & $47.8 \pm 3.5(40.7-54.9)$ & 0.18 \\
\hline & $34 \pm 6(34-35)$ & $36 \pm 1(34-38)$ & $35 \pm 1(33-36)$ & $33 \pm 1(32-35)$ & 0.16 \\
\hline & $13 \pm 29(7-19)$ & $14 \pm 8(4-32)$ & $7 \pm 3(2-13)$ & $23 \pm 7(9-36)$ & 0.05 \\
\hline & $41.6 \pm 25.8(36.1-47.2)$ & $51.6 \pm 5.4(39.5-63.6)$ & $41.3 \pm 3.9(33.5-49.1)$ & $37.9 \pm 5.0(27.5-48.3)$ & 0.34 \\
\hline & $2259 \pm 506(1254-3265)$ & $1332 \pm 611(30-2695)$ & $1941 \pm 629(677-3205)$ & $3215 \pm 1131(895-5535)$ & 0.44 \\
\hline \multirow[t]{4}{*}{ Coronary angiogram } & $n=84$ & $n=10$ & $n=45$ & $n=29$ & 0.40 \\
\hline & $13(15.5 \%)$ & $2(20 \%)$ & $5(11.1 \%)$ & $6(20.7 \%)$ & \\
\hline & 37 (44.0\%) & $6(60 \%)$ & $18(40 \%)$ & $13(44.8 \%)$ & \\
\hline & $34(40.5 \%)$ & $2(20 \%)$ & $22(48.9 \%)$ & $10(34.5 \%)$ & \\
\hline
\end{tabular}


Table 1 Continued

\begin{tabular}{|c|c|c|c|c|c|}
\hline & \multirow[b]{2}{*}{ Total cohort $(n=150)$} & \multicolumn{3}{|c|}{ Fried frailty phenotype } & \multirow[b]{2}{*}{$P$ value } \\
\hline & & Non-frail $n=19$ & Pre-frail $n=89$ & Frail $n=42$ & \\
\hline \multirow[t]{3}{*}{ Management } & $84(56.0 \%)$ & $10(52.6 \%)$ & $51(57.3 \%)$ & $23(54.8 \%)$ & \multirow[t]{3}{*}{0.13} \\
\hline & $51(34 \%)$ & $8(42.1 \%)$ & $25(28.1 \%)$ & $18(42.9 \%)$ & \\
\hline & $15(10 \%)$ & $1(5.3 \%)$ & $13(14.6 \%)$ & $1(2.4 \%)$ & \\
\hline $\begin{array}{l}\text { Predicted in-hospital mortality } \\
\text { risk (GRACE score) }\end{array}$ & $5.2 \% \pm 8.6 \%$ & $3.1 \% \pm 3.3 \%$ & $4.4 \% \pm 7.1 \%$ & $7.7 \% \pm 12.0 \%$ & 0.06 \\
\hline $\begin{array}{l}\text { Predicted 1-year mortality risk } \\
\text { (GRACE score) }\end{array}$ & $15.2 \pm 14.7$ & $11 \% \pm 7 \%$ & $14 \% \pm 12 \%$ & $20 \pm 20$ & 0.01 \\
\hline $\begin{array}{l}\text { Operative mortality risk } \\
\text { (EuroScore II) }\end{array}$ & $5.0 \% \pm 4.8 \%$ & $3.9 \% \pm 4.0 \%$ & $4.0 \% \pm 3.7 \%$ & $7.4 \% \pm 6.4 \%$ & $<0.01$ \\
\hline SF-12 PCS score & $37.1 \pm 10.7$ & $43.5 \pm 7.6$ & $38.8 \pm 11.3$ & $30.5 \pm 7.1$ & 0.005 \\
\hline SF-12 MCS score & $51.7 \pm 11.3$ & $57.1 \pm 6.4$ & $52.7 \pm 10.7$ & $47.4 \pm 12.8$ & 0.003 \\
\hline
\end{tabular}

Data presented as mean \pm SD or $\mathrm{n}(\%)$.

CABG, coronary artery bypass graft surgery; CCS, Canadian Cardiovascular Society; CKD, chronic kidney disease; GRACE, Global Registry of Acute Coronary Events; h/o, history of; LV, left ventricle; SF-12 MCS, Short form-12 mental composite score; NYHA, New York Heart Association; PCI, percutaneous coronary intervention; ; SF-12 PCS, Short form-12 physical composite score.

into the multiple regression model. Participants lost to follow-up were excluded from the follow-up analysis. No imputations were used for missing data. The incidence rate of each outcome variable was calculated. The association between the pre-specified variables and outcome was investigated with regression model and time to event analysis was expressed using Kaplan-Meier curve.

\section{RESULTS}

A total of 150 participants were recruited; frailty was identified in $42(28.0 \%)$ by FFP and $39(26.1 \%)$ by EFS. The baseline characteristics of the total cohort and by frailty status (FFP) are presented in table 1. Majority of the participants had some features of frailty $(87.3 \%)$. Frail patients were older and had a significantly higher mean Charlson's comorbidity score (7.5 \pm 2.4$)$. The clinical presentation was with acute coronary syndrome in $82(54.7 \%)$ though proportionately greater in the frail group $(n=28$, $66.7 \%$ as compared with $\mathrm{n}=9,47.4 \%$ in the non-frail group and $\mathrm{n}=44,50.6 \%$ in the pre-frail group, $\mathrm{p}=0.02$ ). Coronary angiography was undertaken in 96 (64.0\%), with multivessel disease identified in $78(81.3 \%)$.

The QoL score by SF-12 was divided into a physical composite score (SF-12 PCS) and a mental composite score (SF-12 MCS). As compared with a control population, the SF-12 PCS was found to be far below expected in $98(65.3 \%)$ and the SF-12 MCS was far below expected in $27(18.0 \%)$. As shown in table 1 , both measures of QoL were significantly lower with increasing levels of frailty.

\section{Relationship between frailty and QoL}

Tables 2 and 3 depict the multiple variable regression and backwards stepwise regression analysis of the relationship between frailty and QoL as judged by the SF-12 PCS and MCS, respectively, at baseline. There was a significant association between the SF-12 PCS score and female sex, previous PCI, CCS angina class, NYHA class, Charlson comorbidity score and FFP (table 2). The adjusted $\mathrm{R}^{2}$ value was 0.33 for this regression model. There was a significant association between the SF-12 MCS score and age, history of diabetes mellitus and EFS (table 3). The adjusted $R^{2}$ value for this regression model was 0.35 .

\section{Overlap between frailty, comorbidity and disability}

There was considerable overlap observed between frailty, comorbidity and disability in this elderly cohort with $20 \%$ of the participants were both frail and had at least one comorbidity and disability. None of the participants in the frail group were free from comorbidity or disability as calculated from IADL score (figure 1).

\section{Association of frailty with short-term survival and major adverse events}

The overall mortality rate was $9.3 \%$ with the lowest survival in the frail group (figure 2). As outlined in table 4, a major adverse cardiovascular event occurred in $24.7 \%$. Frail patients were significantly more likely to have an acute kidney injury.

Of the participants enrolled as an inpatient, patients with frailty had significantly longer duration of hospital stay (mean 6.5 days compared with 2.7 days for patients who were not frail).

\section{Assessment of frailty and QoL at follow-up}

Of the 136 patients who survived, 103 had a follow-up assessment $(75.7 \%)$ with results outlined in table 5 . There was a significant improvement in both angina class as well as NYHA class. There was no significant alteration in overall frailty status or the PCS of QoL. However, the mental composite score of QoL did significantly improve. This may be a result of improvement in symptoms as suggested by improvement in CCS angina and NYHA class. 
Table 2 Multiple variable regression and backward stepwise regression showing relationship between frailty and SF-12 physical composite score

\begin{tabular}{|c|c|c|c|c|}
\hline \multirow[b]{2}{*}{ SF-12 PCS at baseline } & \multicolumn{2}{|c|}{$\begin{array}{l}\text { Multiple variable regression } \\
\text { (Adj } R^{2}=0.32 \text { ) }\end{array}$} & \multicolumn{2}{|c|}{$\begin{array}{l}\text { Backwards stepwise regression } \\
\text { (Adj } R^{2}=0.33 \text { ) }\end{array}$} \\
\hline & $\beta(95 \% \mathrm{Cl})$ & $P$ value & $\beta(95 \% \mathrm{Cl})$ & $P$ value \\
\hline Age & $-0.12(-0.66$ to 0.42$)$ & 0.64 & & \\
\hline Female sex & $-3.58(-7.24$ to 0.59$)$ & 0.05 & $-2.90(-6.11$ to -0.32$)$ & 0.07 \\
\hline BMI & $-0.14(-0.51$ to 0.23$)$ & 0.45 & & \\
\hline \multicolumn{5}{|l|}{ Medical history } \\
\hline Hypertension & $-1.15(-4.66$ to 2.36$)$ & 0.52 & & \\
\hline Diabetes mellitus & $-0.90(-4.79$ to 2.99$)$ & 0.65 & & \\
\hline Previous MI & $0.49(-4.15$ to 5.13$)$ & 0.84 & & \\
\hline Previous PCl & $-3.82(-8.22$ to 0.57$)$ & 0.09 & $-3.15(-6.34$ to 0.03$)$ & 0.05 \\
\hline \multicolumn{5}{|l|}{ Baseline CCS class } \\
\hline No angina & 0.00 & 0.06 & 0.00 & 0.06 \\
\hline Class I & $-0.68(-7.34$ to 7.48$)$ & & $-0.81(-7.50$ to 5.87$)$ & \\
\hline Class II & -2.31 (-8.78 to 4.17$)$ & & -3.76 (-9.69 to 2.18$)$ & \\
\hline Class III & $-6.14(-12.34$ to 0.06$)$ & & $-6.41(-16.44$ to -0.64$)$ & \\
\hline Class IV & $-8.06(-17.42$ to 1.31$)$ & & -2.67 (-8.76 to 3.40$)$ & \\
\hline \multicolumn{5}{|l|}{ Baseline NYHA class } \\
\hline Class I & 0.00 & 0.04 & 0.00 & 0.004 \\
\hline Class II & $-4.68(-11.07$ to 1.70$)$ & & $-4.76(-10.83$ to 1.32$)$ & \\
\hline Class III & $-8.73(-15.93$ to -1.53$)$ & & $-9.77(-16.44$ to -3.12$)$ & \\
\hline Class IV & $-2.27(-12.53$ to 7.99$)$ & & $-2.92(-12.19$ to 6.35$)$ & \\
\hline Charlson comorbidity score & $-0.74(-1.47$ to 0.14$)$ & 0.14 & $-0.96(-1.72$ to -0.21$)$ & 0.01 \\
\hline GRACE 1-year mortality & $-0.05(-0.21$ to 0.11$)$ & 0.54 & & \\
\hline EuroScore II & $0.84(-0.39$ to 0.56$)$ & 0.73 & & \\
\hline \multicolumn{5}{|l|}{ Clinical presentation } \\
\hline Stable angina & 0.00 & 0.13 & & \\
\hline Unstable angina & $-4.61(-10.03$ to 0.81$)$ & & & \\
\hline NSTEMI & $0.52(-3.96$ to 5.00$)$ & & & \\
\hline STEMI & $6.54(-3.05$ to 16.13$)$ & & & \\
\hline \multicolumn{5}{|l|}{ Fried frailty phenotype } \\
\hline Not frail & 0.00 & 0.05 & 0.00 & 0.005 \\
\hline Pre-frail & -0.05 (-5.04 to 4.94$)$ & & $-1.44(-6.05$ to 3.17$)$ & \\
\hline Frail & $-5.42(-11.89$ to 1.04$)$ & & $-7.29(-12.83$ to 1.75$)$ & \\
\hline \multicolumn{5}{|l|}{ Edmonton frailty score } \\
\hline Not frail & 0.00 & 0.82 & & \\
\hline Vulnerable & -0.36 (-4.48 to 3.76$)$ & & & \\
\hline Mild frailty & -3.01 (-8.36 to 2.33$)$ & & & \\
\hline Moderate frailty & $0.37(-6.34$ to 7.07$)$ & & & \\
\hline Severe frailty & $-0.77(-9.84$ to 8.29$)$ & & & \\
\hline
\end{tabular}

\section{DISCUSSION}

In this study, we have evaluated an unselected group of patients aged $\geq 80$ years attending hospital primarily due to coronary artery disease. For the first time, we have enrolled all-comers irrespective of treatment therefore removing bias present in previous registries that have included only those patients offered revascularisation. We have shown that frailty is common and seen in more than a quarter of patients. Frailty increased with age and was associated with a high comorbidity score and reduced QoL. At short-term follow-up, frail patients were less likely to survive. 
Table 3 Multiple variable regression and backward stepwise regression showing relationship between frailty and SF-12 mental composite score

\begin{tabular}{|c|c|c|c|c|}
\hline \multirow[b]{2}{*}{ SF-12 MCS score at baseline } & \multicolumn{2}{|c|}{$\begin{array}{l}\text { Multiple linear regression } \\
\text { (adjusted } \mathrm{R}^{2}=0.33 \text { ) }\end{array}$} & \multicolumn{2}{|l|}{$\begin{array}{l}\text { Stepwise regression } \\
\text { (adjusted } \mathbf{R}^{2}=0.35 \text { ) }\end{array}$} \\
\hline & $\beta(95 \% \mathrm{Cl})$ & $P$ value & $\beta(95 \% \mathrm{Cl})$ & $P$ value \\
\hline Age & 1.01 (0.45 to 1.57$)$ & 0.00 & 0.83 (0.35 to 1.32$)$ & $<0.01$ \\
\hline Female & -2.09 (-5.86 to 1.69$)$ & 0.28 & & \\
\hline BMI & $-0.05(-0.43$ to 0.33$)$ & 0.79 & & \\
\hline \multicolumn{5}{|l|}{ Medical history } \\
\hline Hypertension & $1.85(-1.78$ to 5.49$)$ & 0.31 & & \\
\hline Diabetes mellitus & $-4.03(-8.07$ to to 0.01$)$ & 0.05 & $-2.74(-6.34$ to 0.89$)$ & 0.03 \\
\hline Previous MI & $2.90(-1.90$ to 7.71$)$ & 0.23 & & \\
\hline Previous PCl & $-1.87(-6.42$ to 2.68$)$ & 0.42 & & \\
\hline \multicolumn{5}{|l|}{ Baseline CCS class } \\
\hline No angina & 0.00 & 0.52 & & \\
\hline Class I & 3.14 (-4.53 to 10.81$)$ & & & \\
\hline Class II & 3.07 (-3.64 to 9.77$)$ & & & \\
\hline Class III & $0.03(-6.39$ to 6.45$)$ & & & \\
\hline Class IV & $4.76(-4.93$ to 14.46$)$ & & & \\
\hline \multicolumn{5}{|l|}{ Baseline NYHA class } \\
\hline Class I & 0.00 & 0.07 & 0.00 & 0.20 \\
\hline Class II & $0.93(-5.68$ to 7.54$)$ & & $1.23(-4.85$ to 7.30$)$ & \\
\hline Class III & $6.29(-1.16$ to 13.74$)$ & & $4.78(-2.05$ to 11.62$)$ & \\
\hline Class IV & $2.73(-7.90$ to 13.35$)$ & & $0.15(-9.41$ to 9.71$)$ & \\
\hline Charlson comorbidity score & $-0.69(-1.72$ to 0.34$)$ & 0.19 & $-0.47(-1.26$ to 0.31$)$ & 0.24 \\
\hline GRACE 1-year mortality & $-0.08(-0.25$ to 0.92$)$ & 0.37 & & \\
\hline EuroScore II & $-0.10(-0.59$ to 0.40$)$ & 0.70 & & \\
\hline \multicolumn{5}{|l|}{ Clinical presentation } \\
\hline Stable angina & 0.00 & 0.60 & & \\
\hline Unstable angina & 0.70 (-4.91 to 6.31$)$ & & & \\
\hline NSTEMI & 0.27 (-4.37 to 4.91$)$ & & & \\
\hline STEMI & $-5.86(-15.8$ to 4.07$)$ & & & \\
\hline \multicolumn{5}{|l|}{ Fried score } \\
\hline Not frail & 0.00 & 0.77 & & \\
\hline Pre-frail & $-1.70(-6.87$ to 3.47$)$ & & & \\
\hline Frail & -0.94 (-7.63 to 5.75$)$ & & & \\
\hline \multicolumn{5}{|l|}{ Edmonton frailty score } \\
\hline Not frail & 0.00 & 0.00 & 0.00 & $<0.01$ \\
\hline Vulnerable & $-11.45(-15.7$ to 7.1$)$ & & $-11.23(-15.11$ to 7.35$)$ & \\
\hline Mild frailty & $-4.85(-10.38$ to 0.69$)$ & & $-5.88(-10.91$ to 0.85$)$ & \\
\hline Moderate frailty & -14.25 (-21.19 to 7.31$)$ & & $-14.13(-20.29$ to 7.96$)$ & \\
\hline Severe frailty & -21.63 (-31.0 to 12.24$)$ & & -22.05 (-29.52 to 14.5$)$ & \\
\hline
\end{tabular}

However, those who underwent follow-up demonstrated an improvement in symptoms (CCS and NYHA class) and mental well-being.

The American Heart Association and European Society of Cardiology both recommend screening elderly patients with CAD and acute coronary syndromes for frailty, cognitive decline and comorbid conditions and to take these factors into consideration while formulating their management plans. ${ }^{421}$ There is a high prevalence of frailty in elderly patients with cardiovascular disease and an increased incidence of subclinical cardiovascular disease in patients with frailty. ${ }^{22} 23$ 


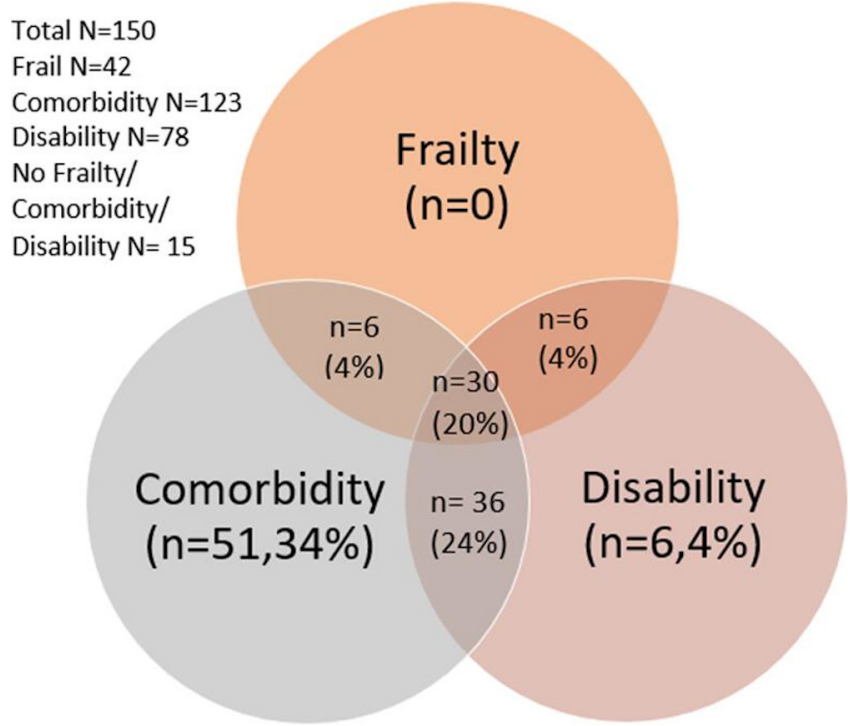

Figure 1 Venn diagram showing overlap of frailty, disability and comorbidity in study cohort. Frailty was derived from Fried frailty phenotype. Disability was derived from IADL scores and comorbidity was calculated from Charlson comorbidity scores.

In accordance with our study, there is growing evidence of a strong association between frailty and poor QoL. ${ }^{24}{ }^{25}$ It could be hypothesised that QoL might improve following coronary intervention primarily due to relief of angina symptoms. In our study, as evidenced by an improvement in CCS and NYHA class, symptoms did improve at follow-up and this was associated with a significant improvement in the MCS of QoL. However, there was no change in the PCS nor the frailty status suggesting that the CAD treatment has limited benefit in this regard. Instead, we have demonstrated considerable overlap between frailty, comorbidity and disability, and it is likely that the high burden of comorbidities is an important driver of QoL. This highlights the need to take a holistic approach in managing frail and pre-frail elderly patients rather than just focusing on treating the CAD in isolation.

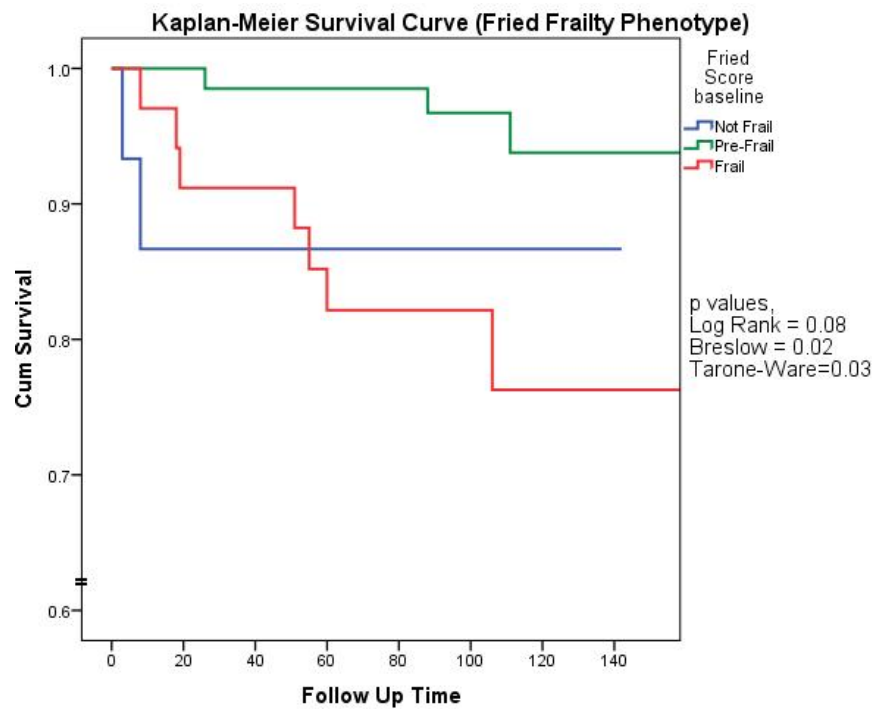

Figure 2 Kaplan-Meier curve showing survival curves of frailty subgroups as per Fried frailty phenotype.

The importance of identifying frailty was recognised in 2017/2018 when the National Health Service introduced routine frailty screening for patients aged $\geq 65$ years to the General Practitioner contract, the aim being to identify people living with frailty and place measures to enable them to live independently for as long as possible. Various interventions may also be of value in people with frailty. A recent systematic review analysed 21 randomised controlled trials that enrolled 5275 older adults with a variety of interventions. ${ }^{26}$ The majority were recruited in a community setting and the review found that, although results were mixed, physical exercise programmes were generally effective at reducing or postponing frailty but only when conducted in groups. One multifactorial interdisciplinary study of 241 community-dwelling patients with frailty demonstrated that those randomised to intervention had significantly less frailty at 1 year as compared with those in the usual care group. Importantly, in the 'very frail' subgroup the intervention was both more effective and less costly than the control. ${ }^{27}$ Although

Table 4 Adverse clinical events for the whole cohort as well as by Fried frailty status occurring at a mean follow-up of 107 days

\begin{tabular}{|c|c|c|c|c|c|}
\hline & Fried frailty phenoty & & & & \\
\hline & Total cohort $(n=150)$ & Not frail $(n=19)$ & Pre-frail (n=89) & Frail $(n=42)$ & $P$ value \\
\hline MACE $^{*}$ & $37(24.7 \%)$ & $8(42.1 \%)$ & $16(18.0 \%)$ & $13(31.0 \%)$ & 0.31 \\
\hline Death & $14(9.3 \%)$ & $2(10.5 \%)$ & $5(5.6 \%)$ & $7(16.7 \%)$ & 0.13 \\
\hline Myocardial infarction & $8(5.3 \%)$ & $2(10.5 \%)$ & $3(3.4 \%)$ & $3(7.1 \%)$ & 0.37 \\
\hline CVA & $3(2.0 \%)$ & $1(5.3 \%)$ & $1(1.1 \%)$ & $1(2.4 \%)$ & 0.49 \\
\hline TIA & $5(3.3 \%)$ & $1(5.3 \%)$ & $3(3.4 \%)$ & $1(2.4 \%)$ & 0.84 \\
\hline Major bleed & $12(8.0 \%)$ & $3(15.85)$ & $7(7.9 \%)$ & $2(4.8 \%)$ & 0.34 \\
\hline AKI & $26(17.3 \%)$ & $3(15.8 \%)$ & $10(11.2 \%)$ & $13(31.0 \%)$ & 0.02 \\
\hline
\end{tabular}

${ }^{*}$ MACE was defined as the composite of death, myocardial infarction, stroke or major bleeding.

AKI, acute kidney injury; CVA, cerebrovascular accident; MACE, major adverse cardiac event; TIA, transient ischaemic event. 
Table 5 Table showing frailty and quality of life scores in patients who attended both a baseline as well as a follow-up assessment $(n=103)$

\begin{tabular}{|c|c|c|c|c|}
\hline$n=103$ & & Baseline assessment & Follow-up & $P$ value \\
\hline \multirow[t]{10}{*}{ Clinical characteristics } & Age & $83.6 \pm 3.0(83.0-84.1)$ & & \\
\hline & Female & $33(32.0 \%)$ & & \\
\hline & BMI & $27.3 \pm 4.0(26.5-28.1)$ & & \\
\hline & h/o Hypertension & $64(62.1 \%)$ & & \\
\hline & $\mathrm{h} / \mathrm{o}$ Diabetes & $25(24.8 \%)$ & & \\
\hline & h/o Previous Ml & $46(44.7 \%)$ & & \\
\hline & $\mathrm{h} / 0 \mathrm{CKD}$ & & & \\
\hline & Creat clearance $>85$ & $7(6.8 \%)$ & & \\
\hline & Creat clearance 50-85 & $45(43.7 \%)$ & & \\
\hline & Creat clearance $<50$ & $50(48.5 \%)$ & & \\
\hline \multirow[t]{3}{*}{ Coronary angiography $(n=59)$} & Single-vessel disease & $12(20.3 \%)$ & & \\
\hline & Two-vessel disease & $24(40.7 \%)$ & & \\
\hline & Three-vessel disease & $23(39.0 \%)$ & & \\
\hline \multirow[t]{4}{*}{ LV function $(n=79)$} & LVEF $\geq 55$ & $43(54.4 \%)$ & & \\
\hline & LVEF $46 \%-54 \%$ & $18(22.8 \%)$ & & \\
\hline & LVEF $36 \%-45 \%$ & $13(16.5 \%)$ & & \\
\hline & Severe LVEF $\leq 35 \%$ & $5(6.3 \%)$ & & \\
\hline \multirow[t]{5}{*}{ CCS angina class } & No chest pain & $7(6.8 \%)$ & $61(59.2 \%)$ & $<0.001$ \\
\hline & CCS class I & $15(14.6 \%)$ & $17(16.5 \%)$ & \\
\hline & CCS class II & $33(32.0 \%)$ & $20(19.4 \%)$ & \\
\hline & CCS class III & $32(31.1 \%)$ & $5(4.9 \%)$ & \\
\hline & CCS class IV & $16(15.5 \%)$ & $0(0.0 \%)$ & \\
\hline \multirow[t]{4}{*}{ NYHA class } & NYHA class I & $6(5.8 \%)$ & $17(16.5 \%)$ & 0.05 \\
\hline & NYHA class II & $64(62.1 \%)$ & $55(53.4 \%)$ & \\
\hline & NYHA class III & $29(28.2 \%)$ & $27(26.2 \%)$ & \\
\hline & NYHA class IV & $4(3.9 \%)$ & $4(3.9 \%)$ & \\
\hline \multirow[t]{3}{*}{ Fried frailty phenotype } & Not frail & $13(12.6 \%)$ & $19(18.5 \%)$ & 0.56 \\
\hline & Pre-frail & $62(60.2 \%)$ & $54(52.4 \%)$ & \\
\hline & Frail & $28(27.2 \%)$ & $30(29.1 \%)$ & \\
\hline \multirow[t]{5}{*}{ Edmonton frailty score } & Not frail & $60(58.3 \%)$ & $60(58.3 \%)$ & 0.66 \\
\hline & Vulnerable & $17(16.5 \%)$ & $19(18.4 \%)$ & \\
\hline & Mild frailty & $15(14.6 \%)$ & $16(15.5 \%)$ & \\
\hline & Moderate frailty & $8(7.8 \%)$ & $4(3.9 \%)$ & \\
\hline & Severe frailty & $3(2.9 \%)$ & $4(3.9 \%)$ & \\
\hline SF-12 physical composite score & & $37.2 \pm 11.0$ & $38.5 \pm 11.3$ & 0.27 \\
\hline \multirow[t]{3}{*}{ Physical health composite score } & At or above & $27(26.2 \%)$ & $33(32.0 \%)$ & 0.19 \\
\hline & Below & $13(12.6 \%)$ & $13(12.6 \%)$ & \\
\hline & Far below & $63(61.2 \%)$ & $56(54.4 \%)$ & \\
\hline SF-12 mental composite score & & $52.7 \pm 11.5$ & $55.1 \pm 10.6$ & 0.04 \\
\hline \multirow[t]{3}{*}{ Mental health composite score } & At or above & $81(78.6 \%)$ & $84(81.6 \%)$ & 0.19 \\
\hline & Below & $4(3.9 \%)$ & $7(6.8 \%)$ & \\
\hline & Far below & $18(17.5 \%)$ & $11(10.7 \%)$ & \\
\hline
\end{tabular}

BMI, body mass index; CCS, Canadian Cardiovascular Society; CKD, chronic kidney disease; h/o, history of; LVEF, left ventricle ejection fraction; MI, myocardial infarction; NYHA, New York Heart Association. 
these studies did not specifically evaluate cardiovascular patients, the benefits of cardiac rehabilitation are well recognised. A meta-analysis of 63 studies (14486 participants) demonstrated that exercise-based cardiac rehabilitation reduces mortality and improves QoL in all age groups. ${ }^{28}$ Paradoxically, although the benefit of rehabilitation is potentially greater in older adults, there is relatively poor uptake. Older patients are particularly prone to deconditioning, frailty and disability, such that the implementation of exercise is often the most difficult. However, a structured physical activity programme that incorporates exercises to improve strength, flexibility, co-ordination and balance as well as aerobic exercise has been shown to be beneficial in patients identified as frail following cardiac surgery. ${ }^{29}$ Strategies are needed to increase participation in rehabilitation programmes and further research is needed to assess whether long-term multidisciplinary interventional programmes can be shown to improve frailty and QoL, and be cost-effective in terms of reducing healthcare costs and hospitalisations. ${ }^{28} 30$

Another finding of the current study is that frailty assessment is complex and measures are not identical. The FFP focuses on weight loss, exhaustion, physical activity, gait speed and grip strength. These are 'physical features' and the FFP was found to be associated with the physical composite score of QoL. This was in addition to the expected association of the physical component of QoL to symptom burden (CCS and NYHA class). On the other hand, the Edmonton score assesses mood as well as cognitive function in addition to physical parameters such as the 'get up and go' test. This enabled the EFS to detect the mental component to QoL. Although not independent, physical and mental elements are both important components of an individual's QoL. This highlights the limitation of using a single frailty index score and emphasises the importance of also encompassing QoL assessment in older patients. The differences between the frailty scores also underpins the difficulties encountered in truly defining frailty, making it challenging to compare studies that use different assessment tools.

Previous studies have demonstrated that frailty is associated with a lower survival rate. ${ }^{31}$ This was also seen in the present study and highlights the need for careful consideration when making management recommendations in frail patients, particularly regarding revascularisation, as the benefits of invasive treatment may not outweigh the risks. Our study also demonstrates that frail patients are at significantly increased risk of acute kidney injury. This is in accordance with a recent study of unselected acute medical admissions aged $\geq 65$ years which demonstrated an association between acute kidney injury on admission and frailty, as well as an increase in early mortality. ${ }^{32}$ Care should therefore be taken in frail patients when considering introducing cardiac medications such as ACE inhibitors and angiotensin receptor blockers which reduce renal blood flow. In addition, hydration status of the frail patients should be assessed carefully prior to undergoing invasive cardiac investigations to help reduce the risk of contrast-induced nephropathy.

For patients admitted with an acute coronary syndrome, the strategy of early coronary angiography and revascularisation will be evaluated in the on-going SENIOR-RITA trial. This study, funded by the British Heart Foundation, is a multicentre prospective open-label trial randomising 2300 patients with NSTEMI, aged $\geq 75$ years, to invasive versus a conservative treatment strategy. The primary outcome is cardiovascular death or non-fatal myocardial infarction at 1 year. Importantly, the study includes assessment of frailty and QoL scores at baseline and up to 5 years. In addition, the multicentre MOSCA-FRAIL study will specifically evaluate frail patients admitted with NSTEMI and randomised to invasive versus a conservative strategy. ${ }^{33}$ For elective patients being considered for surgery, there is a potential role of 'prehabilitation'. Based on respiratory and exercise interventions prescribed prior to surgery, there is evidence that this improves outcomes following cardiac surgery. ${ }^{34}$ However, studies have enrolled low-risk and relatively young patients and there is a lack of data linking its effectiveness in a cohort of older 'frail' or 'prefrail' individuals.

\section{Study limitations}

This is a single-centre study evaluating a predominantly Caucasian population in the North of England. Results cannot therefore be generalised to patients from other ethnic backgrounds. Due to the sample size, the study was not designed to determine causality and a larger multicentre study would be needed. The study is observational and not designed to evaluate the impact of treatment strategy on outcome. In patients who were alive, almost one quarter withdrew from the study (follow-up rate $75.7 \%$ ) despite offering home visits. This highlights the difficulties in undertaking research in this age group and should be factored into determining sample sizes for future studies.

\section{CONCLUSIONS}

In patients referred to hospital with coronary artery disease, frailty is associated with poorer QoL, a high coexistence of comorbidities, a high burden of cardiovascular symptoms and a high short-term mortality rate. Following cardiac treatment, patients had an increase in the mental component of QoL. There was no change in the physical aspect of QoL or overall frailty status. Hence, in older adults presenting with symptomatic coronary artery disease, frailty will need to be taken into account in addition to their treatments to improve their overall QoL.

Contributors SQ, MJ and AH contributed to the conceptualisation of the idea, formalised the study design, obtained ethical approval, executed the project, analysed the results and wrote the manuscript. JAR, RC, BD, JJ, RMO, DN and ML provided expert overview of the project, critically reviewed the study proposal and supported the recruitment process.

Funding The study was supported by grant from 'The Hull and East Riding Cardiac Trust Fund'. 
Competing interests None declared.

Patient consent for publication Not required.

Ethics approval The study was approved by the West Midlands-South Birmingham Research Ethics Committee on behalf of Health Research Authority (IRAS 193997, REC ref 16/WM/0195), and written informed consent was obtained from all patients.

Provenance and peer review Not commissioned; externally peer reviewed.

Data availability statement Data are available on reasonable request. All appropriate data requests can be made to AH (angela.hoye@hull.ac.uk).

Open access This is an open access article distributed in accordance with the Creative Commons Attribution Non Commercial (CC BY-NC 4.0) license, which permits others to distribute, remix, adapt, build upon this work non-commercially, and license their derivative works on different terms, provided the original work is properly cited, appropriate credit is given, any changes made indicated, and the use is non-commercial. See: http://creativecommons.org/licenses/by-nc/4.0/.

\section{ORCID iDs}

Shouaib Qayyum http://orcid.org/0000-0003-2960-4185

Jennifer Ann Rossington http://orcid.org/0000-0001-9946-6369

\section{REFERENCES}

1 David Melzer JCD, Winder R, Masoli J. The Age UK almanac of disease profiles in later life-a reference on the frequency of major disease, conditions and syndromes affecting older people in England, 2015.

2 BCIS audit returns, 2018-19. Available: https://www.bcis.org.uk/ resources/audit-results/

3 Johnman C, Mackay DF, Oldroyd KG, et al. Quality of life following percutaneous coronary interventions in octogenarians: a systematic review. Heart 2013;99:779-84.

4 Alexander KP, Newby LK, Cannon CP, et al. Acute coronary care in the elderly, part I: non-ST-segment-elevation acute coronary syndromes: a scientific statement for healthcare professionals from the American Heart Association Council on Clinical Cardiology: in collaboration with the Society of Geriatric Cardiology. Circulation 2007:115:2549-69.

5 Dodd KS, Saczynski JS, Zhao Y, et al. Exclusion of older adults and women from recent trials of acute coronary syndromes. J Am Geriatr Soc 2011:59:506-11.

6 Afilalo J, Alexander KP, Mack MJ, et al. Frailty assessment in the cardiovascular care of older adults. J Am Coll Cardiol 2014;63:747-62.

7 Singh M, Rihal CS, Lennon RJ, et al. Influence of frailty and health status on outcomes in patients with coronary disease undergoing percutaneous revascularization. Circ Cardiovasc Qual Outcomes 2011;4:496-502.

8 Tse G, Gong M, Nunez J, et al. Frailty and mortality outcomes after percutaneous coronary intervention: a systematic review and metaanalysis. J Am Med Dir Assoc 2017;18:1097.e1-10.

9 Lee DH, Buth KJ, Martin B-J, et al. Frail patients are at increased risk for mortality and prolonged institutional care after cardiac surgery. Circulation 2010;121:973-8.

10 Fried LP, Tangen CM, Walston J, et al. Frailty in older adults: evidence for a phenotype. J Gerontol A Biol Sci Med Sci 2001;56:M146-57.

11 Rolfson DB, Majumdar SR, Tsuyuki RT, et al. Validity and reliability of the Edmonton frail scale. Age Ageing 2006;35:526-9.

12 Müller-Nordhorn J, Roll S, Willich SN. Comparison of the Short Form (SF)-12 health status instrument with the SF-36 in patients with coronary heart disease. Heart 2004;90:523-7.

13 Ware J A, Kosinski M D, Keller S. SF-12: how to score the SF-12 physical and mental health summary scales, 1998.
14 Campeau L. The Canadian Cardiovascular Society grading of angina pectoris revisited 30 years later. Can J Cardiol 2002;18:371-9.

15 Cox J, Naylor CD. The Canadian Cardiovascular Society grading scale for angina pectoris: is it time for refinements? Ann Intern Med 1992;117:677-83.

16 Dolgin MAN, Fox AC, Gorlin R, et al. Nomenclature and criteria for diagnosis of diseases of the heart and great vessels. 9th edn. Lippincott Williams and Wilkins, 1994.

17 GRACE Investigators. Rationale and design of the GRACE (Global Registry of Acute Coronary Events) project: a multinational registry of patients hospitalized with acute coronary syndromes. Am Heart J 2001;141:190-9.

18 Nashef SAM, Roques F, Sharples LD, et al. EuroSCORE II. Eur J Cardiothorac Surg 2012;41:734-45.

19 Mehran R, Rao SV, Bhatt DL, et al. Standardized bleeding definitions for cardiovascular clinical trials: a consensus report from the Bleeding Academic Research Consortium. Circulation 2011;123:2736-47.

20 Vranckx P, White HD, Huang Z, et al. Validation of BARC bleeding criteria in patients with acute coronary syndromes: the TRACER trial. J Am Coll Cardiol 2016;67:2135-44.

21 Walker DM, Gale CP, Lip G, et al. Editor's Choice-Frailty and the management of patients with acute cardiovascular disease: a position paper from the Acute Cardiovascular Care Association. Eur Heart J 2018;7:176-93.

22 Newman AB, Gottdiener JS, McBurnie MA, et al. Associations of subclinical cardiovascular disease with frailty. J Gerontol A Biol Sci Med Sci 2001;56:M158-66.

23 Afilalo J, Karunananthan S, Eisenberg MJ, et al. Role of frailty in patients with cardiovascular disease. Am J Cardiol 2009;103:1616-21.

24 Kojima G, Iliffe S, Jivraj S, et al. Association between frailty and quality of life among community-dwelling older people: a systematic review and meta-analysis. J Epidemiol Community Health 2016;70:716-21.

25 Spertus JA, Salisbury AC, Jones PG, et al. Predictors of qualityof-life benefit after percutaneous coronary intervention. Circulation 2004;110:3789-94

26 Apóstolo J, Cooke R, Bobrowicz-Campos E, et al. Effectiveness of interventions to prevent pre-frailty and frailty progression in older adults: a systematic review. JBI Database System Rev Implement Rep 2018;16:140-232.

27 Fairhall N, Sherrington C, Kurrle SE, et al. Economic evaluation of a multifactorial, interdisciplinary intervention versus usual care to reduce frailty in frail older people. J Am Med Dir Assoc 2015;16:41-8.

28 Anderson L, Oldridge N, Thompson DR, et al. Exercise-based cardiac rehabilitation for coronary heart disease: Cochrane systematic review and meta-analysis. J Am Coll Cardiol 2016;67:1-12.

29 Molino-Lova R, Pasquini G, Vannetti F, et al. Effects of a structured physical activity intervention on measures of physical performance in frail elderly patients after cardiac rehabilitation: a pilot study with 1-year follow-up. Intern Emerg Med 2013;8:581-9.

30 Suaya JA, Stason WB, Ades PA, et al. Cardiac rehabilitation and survival in older coronary patients. J Am Coll Cardiol 2009;54:25-33.

31 Klein BEK, Klein R, Knudtson MD, et al. Frailty, morbidity and survival. Arch Gerontol Geriatr 2005;41:141-9.

32 Morton S, Isted A, Avery P, et al. Is frailty a predictor of outcomes in elderly inpatients with acute kidney injury? A prospective cohort study. Am J Med 2018;131:e1252:1251-6.

33 Sanchis J, Ariza-Solé A, Abu-Assi E, et al. Invasive versus conservative strategy in frail patients with NSTEMI: the MOSCAFRAIL clinical trial study design. Rev Esp Cardiol 2019;72:154-9.

34 McCann M, Stamp N, Ngui A, et al. Cardiac prehabilitation. J Cardiothorac Vasc Anesth 2019;33:2255-65. 